\title{
One-Year Follow-Up of Girls with Precocious Puberty and Their Mothers: Do Psychological Assessments Change over Time or with Treatment?
}

\author{
Melissa J. Schoelwer ${ }^{a}$ Kelly L. Donahue ${ }^{b}$ Paula Didrick $^{a}$ Erica A. Eugster ${ }^{a}$ \\ a Pediatrics, Section of Pediatric Endocrinology, Riley Hospital for Children, Indianapolis, IN, USA; b Pediatrics, \\ Section of Adolescent Medicine, Indiana University School of Medicine, Indianapolis, IN, USA
}

\section{Keywords \\ Central precocious puberty $\cdot \mathrm{GnRH}$ analog . \\ Psychopathology · Premature adrenarche}

\begin{abstract}
Background: To determine whether psychological characteristics of girls with variations of early puberty and their mothers change over time and with treatment in girls with central precocious puberty (CPP). Methods: Girls with CPP, premature adrenarche (PA), and early normal puberty (ENP) completed psychological assessments at baseline and after 1 year along with their mothers. All girls with CPP were treated with GnRH analogs. Psychological effects of group and time were examined using $2 \times 3$ mixed ANOVAs. Results: Sixty-two subjects aged 7.5 \pm 1.4 years (range 4.8-10.5) were enrolled, of whom 36 (15 with CPP, 8 with PA, and 13 with ENP) completed 1-year follow-up assessments. Psychological measures were normal in all girls. No significant group differences were found for any measure of girls' psychological functioning at either time point. However, across all groups there was change over time with a decrease in perceived physical competence $(p<0.001)$ and an increase in perceived maternal acceptance $(p=0.001)$. Conclusion: No abnormalities in psychological functioning were found
\end{abstract}

\section{KARGER}

() 2017 S. Karger AG, Basel

E-Mail karger@karger.com

www.karger.com/hrp among girls with variations of early puberty, and all groups were in the normal range. Our results are largely reassuring regarding concerns of adverse psychological consequences of early puberty in girls.

(c) 2017 S. Karger AG, Basel

\section{Introduction}

Precocious puberty in girls is classically defined as the appearance of secondary sexual development prior to age 8 years. Etiologies include central precocious puberty (CPP), which results from early activation of the hypothalamic-pituitary-gonadal (HPG) axis, and variants such as premature adrenarche (PA), typified by early pubic and/or axillary hair and/or adult body odor. One of the most common concerns about precocious puberty in girls is the potential for adverse psychological consequences [1]. Literature to date has linked earlier-than-average puberty to higher rates of depression [2-6], anxiety $[2,6,7]$, substance abuse $[3,8]$, delinquency [9], and criminality [8] than in girls with on-time development. However, whether and to what extent these findings can be extrapolated to girls with precocious puberty is unknown. 
Thus far, data on psychological aspects of precocious puberty in girls are inconsistent and limited. GnRH analogs (GnRHa) are the gold-standard treatment of CPP and are highly effective in suppressing the HPG axis [10]. While the primary medical reason for the treatment of CPP is to preserve adult height potential, a second frequently cited reason is to alleviate psychological distress associated with early pubertal development [11]. To what degree girls with CPP actually experience such distress and whether treatment with GnRHa alters the psychological trajectory in these patients is unknown. Although considered a variation of normal development, some studies have suggested an increased risk for psychopathology and behavioral problems in girls with PA [1214]. How common these issues are in girls with PA and whether they change over time has likewise not been explored. While parental distress secondary to a child's early puberty has also been reported, whether mothers of all girls with forms of precocious puberty experience psychological difficulty has not been examined $[15,16]$.

We previously reported normal baseline psychological functioning at the time of diagnosis in girls with CPP, PA, and early normal puberty (ENP), with no significant differences between groups. However, we found that mothers of girls with PA reported higher scores on measures of depression and stress than mothers of girls with ENP [17]. The aim of this follow-up study was to determine if psychological characteristics of girls with early puberty and their mothers change over time and with treatment in those with CPP.

\section{Methods}

Girls with CPP, PA, or ENP and their mothers were prospectively recruited from the Pediatric Endocrine Clinic at Riley Hospital for Children at Indiana University Health in Indianapolis, IN, USA. The study was approved by the Indiana University School of Medicine Institutional Review Board. Assent was obtained from all girls aged 7 years and older along with written informed consent from all mothers. Inclusion criteria for CPP consisted of pubertal onset prior to 8 years of age along with biochemical confirmation of HPG axis activation (random ultrasensitive $\mathrm{LH}>0.3 \mathrm{mIU} / \mathrm{mL}$ or GnRHa stimulation test with peak $\mathrm{LH}>4 \mathrm{mIU} / \mathrm{mL}$ ). Inclusion criteria for PA included age between 5 and 8 years along with clinical, radiographic, and biochemical features consistent with this diagnosis. Inclusion criteria for ENP included age between 7.5 and 10 years as well as clinical and radiographic evidence of central puberty. Exclusion criteria for all groups included inability to speak English, prior treatment with GnRHa, and developmental delay or significant behavior problems precluding cooperation with an interview. All girls with CPP were treated with GnRHa. Psychological assessments of the girls and their mothers were per- formed at baseline and at 1-year follow-up and included measures of psychological function of the child, obtained from self- and mother report, and psychological function of the mother, obtained from self-report. Details of the methods used have previously been published [17] and will be briefly recapped here.

Girls completed the Children's Depression Inventory (CDI) and the Harter Pictorial Scale of Perceived Competence and Social Acceptance for Young Children, and their mothers completed the Child Behavior Checklist (CBCL). The CDI measures depressive symptoms in the previous 2 weeks on a three-point scale with higher scores indicating more depressive symptoms [18]. The Harter scale assesses 4 dimensions of a child's perceived self-competence: cognitive competence, physical competence, peer acceptance, and maternal acceptance [19]. It is scored using a four-point scale with higher scores indicating a higher level of perceived competence or acceptance. The CBCL measures behavioral and emotional problems in children on a three-point scale from which T-scores were calculated for Internalizing, Externalizing, and Total Behavior Problems [20].

Mothers completed the NEO Five-Factor Inventory-3 (NEOFFI-3), the Depression, Anxiety and Stress Scale (DASS), and the Positive and Negative Affect Schedule (PANAS). The NEO-FFI-3 measures 5 domains of personality (neuroticism, extraversion, openness, agreeableness, and conscientiousness) on a five-point Likert scale with high scores indicating a high degree of the personality trait [21]. The DASS measures depression, anxiety, and stress experienced over the past week using a four-point scale with high scores indicating a high level of the negative emotional state [22]. The PANAS measures emotions experienced in the previous week using a five-point scale with items corresponding to positive or negative affect scales [23]. All assessments were administered to the girls and their mothers by the same study coordinator (P.D.) at baseline and at 1 year, and required anywhere from 30 to $60 \mathrm{~min}$.

\section{Statistical Analysis}

Differences in age and BMI $z$-score between the CPP, PA, and ENP groups at follow-up were examined using one-way analyses of variance (ANOVA) tests with planned contrasts. A series of 3 (group) $\times 2$ (time) mixed ANOVAs was conducted to determine differences in scores on psychological functioning, with measures of psychological function included as the dependent variables. Analyses were performed using SPSS 24, and type I error was set at 0.05 for all tests.

\section{Results}

Of the 62 subjects initially enrolled, 36 (58\%) completed 1-year follow-up assessments ( 15 with CPP, 8 with PA, and 13 with ENP). The majority of girls with CPP completed follow-up assessments (15/19,79\%), while fewer girls in the PA $(8 / 22,36 \%)$ and ENP $(13 / 21,62 \%)$ groups returned. Missing 1-year assessments were due to girls and their mothers being lost to follow-up. In each case, a minimum of 3 attempts were made by phone to encourage families to schedule their visits. Several families could not be located due to nonworking phone numbers or hav- 
Table 1. Patient characteristics at baseline and 1-year follow-up

\begin{tabular}{|c|c|c|c|}
\hline & $\begin{array}{l}\text { CPP } \\
(n=15)\end{array}$ & $\begin{array}{l}\mathrm{PA} \\
(n=8)\end{array}$ & $\begin{array}{l}\text { ENP } \\
(n=13)\end{array}$ \\
\hline \multicolumn{4}{|l|}{ Age $($ mean $\pm S D)$, years } \\
\hline Baseline & $7.31 \pm 0.72$ & $6.88 \pm 0.89$ & $8.71 \pm 1.33$ \\
\hline Follow-up ${ }^{\mathrm{a}}$ & $8.36 \pm 0.74$ & $8.03 \pm 0.66$ & $9.72 \pm 1.34$ \\
\hline Race, $n$ (\% non-Caucasian) & $5(33)$ & $5(63)$ & $7(54)$ \\
\hline \multicolumn{4}{|l|}{ BMI $z$-score $( \pm \mathrm{SD})$} \\
\hline Baseline & $1.33 \pm 0.59$ & $1.54 \pm 0.98$ & $1.22 \pm 0.51$ \\
\hline Follow-up & $1.42 \pm 0.59$ & $1.57 \pm 1.06$ & $1.46 \pm 0.42$ \\
\hline \multicolumn{4}{|l|}{ Postmenarchal, $n(\%)$} \\
\hline Baseline & $1(7)$ & 0 & $4(31)$ \\
\hline Follow-up & $1(7)$ & 0 & $5(39)$ \\
\hline
\end{tabular}

$\mathrm{CPP}$, central precocious puberty; PA, premature adrenarche; ENP, early normal puberty. ${ }^{\text {a }}$ Significant difference between the ENP group and CPP and PA groups (combined), $\mathrm{p}<0.001$.

ing moved out of the area. Several agreed to come to the clinic but repeatedly missed appointments. Girls who did not complete follow-up were not significantly different than those who did with regard to age, race, and BMI $z$ score. Baseline psychological testing was also not significantly different between those who returned for followup and those who did not for all measures except for perceived cognitive competence, which was higher in those who completed follow-up $(p=0.03)$. Mothers who returned for follow-up reported lower levels of anxiety $(p=$ $0.01)$ and negative affect $(p=0.03)$ on initial assessments.

Patient characteristics at baseline and at 1-year followup are outlined in Table 1 . The girls had an average age of 8.8 years at the time of follow-up (range 6.6-11.5 years). Girls with ENP were significantly older than girls with CPP and PA $(p<0.001)$. BMI $z$-scores of the girls who completed follow-up were not significantly different. Five girls were postmenarchal at baseline. One additional girl in the ENP group reached menarche during follow-up, making for a total of 6 postmenarchal subjects.

The results of the psychological testing in the girls and their mothers at 1-year follow-up are shown in Table 2. All scores on the CDI and CBCL were in the normal range, and no significant group differences were found for any measure of girls' psychological functioning. However, across all groups there was a significant decrease in perceived physical competence $\left(p<0.001, \eta_{p}^{2}=0.461\right)$ on the Harter scale from baseline to 1 year, with the scores in all groups near -2 SDs (2.62) for published normative data (Fig. 1). All girls also reported a significant increase

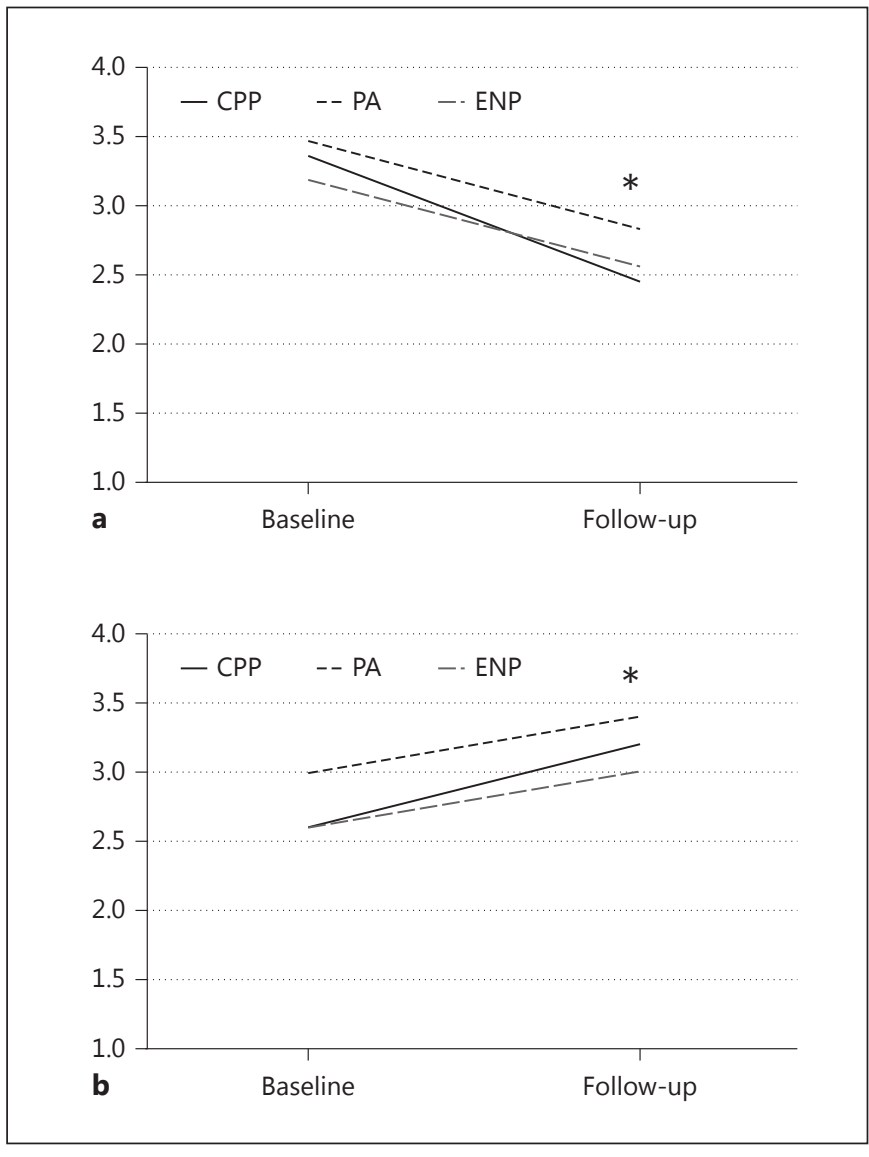

Fig. 1. a Girls' perceived physical competence scores at baseline and follow-up. Significant decrease over time $(p<0.001)$. b Girls' perceived maternal acceptance scores at baseline and follow-up. Significant increase over time $(p=0.001)$.

in perceived maternal acceptance $\left(p=0.001, \eta_{p}^{2}=0.275\right)$ on the Harter scale over time. While no significant group differences were observed in the mothers at 1 year, mothers across all groups reported increased negative affect at follow-up ( $\left.p=0.047, \eta_{p}^{2}=0.115\right)$. Unlike in the initial population of mothers as a whole, the subset of mothers who completed 1-year follow-up did not demonstrate significant differences by group at baseline.

\section{Discussion}

Numerous studies have reported an association between early normal puberty and adverse psychological, behavioral, and social outcomes in girls [2-9]. Sample characteristics of these studies have varied widely and have ranged from meta-analyses to large population- 
Table 2. Psychological assessments at baseline and follow-up (mean score \pm SD)

\begin{tabular}{|c|c|c|c|}
\hline & $\begin{array}{l}\text { CPP } \\
(n=15)\end{array}$ & $\begin{array}{l}\text { PA } \\
(n=8)\end{array}$ & $\begin{array}{l}\text { ENP } \\
(n=13)\end{array}$ \\
\hline \multicolumn{4}{|l|}{ Child assessments } \\
\hline \multicolumn{4}{|l|}{$\mathrm{CDI}^{\mathrm{a}, \mathrm{b}}$} \\
\hline Baseline & $7.8 \pm 6.8$ & $11.5 \pm 5.0$ & $6.7 \pm 4.8$ \\
\hline Follow-up & $6.3 \pm 5.7$ & $5.5 \pm 0.7$ & $4.8 \pm 3.5$ \\
\hline \multicolumn{4}{|l|}{ Harter scale $e^{\mathrm{c}}$} \\
\hline \multicolumn{4}{|c|}{ Cognitive competence } \\
\hline Baseline & $3.8 \pm 0.2$ & $3.7 \pm 0.4$ & $3.6 \pm 0.4$ \\
\hline Follow-up & $3.5 \pm 0.4$ & $3.6 \pm 0.3$ & $3.6 \pm 0.4$ \\
\hline \multicolumn{4}{|c|}{ Peer acceptance ${ }^{b}$} \\
\hline Baseline & $3.2 \pm 0.7$ & $3.4 \pm 0.8$ & $3.1 \pm 0.4$ \\
\hline Follow-up & $3.3 \pm 0.5$ & $3.5 \pm 0.5$ & $3.4 \pm 0.4$ \\
\hline \multicolumn{4}{|c|}{ Physical competence ${ }^{\mathrm{d}}$} \\
\hline Baseline & $3.4 \pm 0.4$ & $3.5 \pm 0.7$ & $3.2 \pm 0.4$ \\
\hline Follow-up & $2.5 \pm 0.7$ & $2.8 \pm 0.7$ & $2.6 \pm 0.4$ \\
\hline \multicolumn{4}{|c|}{ Maternal acceptance $e^{\mathrm{e}}$} \\
\hline Baseline & $2.6 \pm 0.7$ & $3.0 \pm 0.9$ & $2.6 \pm 0.5$ \\
\hline Follow-up & $3.2 \pm 0.6$ & $3.4 \pm 0.7$ & $3.0 \pm 0.6$ \\
\hline \multicolumn{4}{|c|}{ CBCL (T-score) } \\
\hline \multicolumn{4}{|c|}{ Internalizing scale } \\
\hline Baseline & $52.6 \pm 11.4$ & $49.5 \pm 13.5$ & $47.9 \pm 9.1$ \\
\hline Follow-up & $52.9 \pm 12.2$ & $50.9 \pm 9.8$ & $50.2 \pm 9.4$ \\
\hline \multicolumn{4}{|c|}{ Externalizing scale } \\
\hline Baseline & $51.8 \pm 7.8$ & $48.8 \pm 13.4$ & $46.0 \pm 9.7$ \\
\hline Follow-up & $52.1 \pm 7.1$ & $49.5 \pm 14.3$ & $46.6 \pm 8.6$ \\
\hline \multicolumn{4}{|l|}{ Total problems ${ }^{\mathrm{f}}$} \\
\hline Baseline & $51.6 \pm 8.6$ & $44.0 \pm 6.0$ & $47.1 \pm 9.1$ \\
\hline Follow-up & $52.5 \pm 8.9$ & $48.3 \pm 9.4$ & $48.3 \pm 7.8$ \\
\hline \multicolumn{4}{|l|}{ Mother assessments } \\
\hline \multicolumn{4}{|l|}{ NEO-FFI-3 } \\
\hline \multicolumn{4}{|l|}{ Neuroticism } \\
\hline Baseline & $15.7 \pm 4.1$ & $18.1 \pm 8.5$ & $18.8 \pm 6.8$ \\
\hline Follow-up & $16.3 \pm 3.7$ & $20.5 \pm 6.3$ & $17.6 \pm 6.5$ \\
\hline \multicolumn{4}{|l|}{ Extraversion } \\
\hline Baseline & $29.9 \pm 5.6$ & $31.3 \pm 6.9$ & $30.2 \pm 5.8$ \\
\hline Follow-up & $30.0 \pm 4.4$ & $30.3 \pm 3.2$ & $31.2 \pm 5.3$ \\
\hline \multicolumn{4}{|l|}{ Openness } \\
\hline Baseline & $26.1 \pm 5.7$ & $24.0 \pm 4.7$ & $25.4 \pm 5.1$ \\
\hline Follow-up & $25.1 \pm 3.3$ & $26.3 \pm 3.2$ & $26.9 \pm 5.3$ \\
\hline \multicolumn{4}{|l|}{ Agreeableness ${ }^{b}$} \\
\hline Baseline & $32.3 \pm 2.0$ & $32.9 \pm 4.2$ & $33.2 \pm 3.0$ \\
\hline Follow-up & $32.4 \pm 2.3$ & $33.5 \pm 3.1$ & $32.8 \pm 2.9$ \\
\hline
\end{tabular}

based studies of adult women to longitudinal follow-up of adolescent girls. Consistent findings have included a link between early menarche and higher rates of depression, social anxiety, substance abuse, lower academic achievement, and earlier initiation of sexual activity and risk-taking behavior. In contrast, studies examining psychological correlates of precocious puberty in girls have been hampered by small sample sizes and methodological issues,

and conclusions have been conflicting $[24,25]$. For example, some investigators have reported higher rates of depression, suicidal thoughts and behavior problems in girls with precocious puberty compared with controls [26-28]. In contrast, others have failed to find any differences in self-image, self-esteem, or behavior in children with precocious puberty when compared to population norms $[29,30]$. Interestingly, one study even reported 
higher verbal IQ in a mixed group of girls with precocious puberty or PA compared with a control group with normally timed development [31]. Thus, this area has been identified as one that is sorely in need of additional research [32] and it is probably not a coincidence that literature reporting long-term outcomes of GnRHa therapy for CPP generally neglect psychological aspects of followup entirely [33-35]. Clearly, more information regarding this topic is essential. Our study is unique in the comparison of girls with $\mathrm{CPP}$ receiving $\mathrm{GnRHa}$ treatment to girls with PA and ENP. We are aware of only two other studies that examined the effect of GnRHa versus no treatment on psychological outcomes in children with early puberty. The first study evaluated 20 girls with CPP at diagnosis and after 2 years [15]. Fifteen girls were treated with GnRHa and 5 girls were not treated based on the decision of their physician and parents. In contrast with our results, girls with CPP had elevated scores of withdrawal, anxiety, and depression on the CBCL (defined as $>1$ SD above their reference data) at baseline, which persisted after 2 years of treatment. Treatment, however, was associated with reduction in embarrassment about pubertal development, fear of sexuality, and loneliness. Unfortunately, treated girls were not directly compared to untreated girls, so conclusions regarding the impact of $\mathrm{GnRHa}$ treatment are not possible. The second study evaluated psychological functioning in adopted children with early puberty, many of whom would not meet criteria for CPP, before and after treatment with GnRHa alone or in combination with growth hormone [36]. The children showed normal psychological functioning compared to Dutch norms of adopted and nonadopted children both at the start of treatment and after 3 years. Again, there was no untreated control group for comparison. It is clear that there is no consensus regarding psychological outcomes in either treated or untreated children with CPP and a randomized clinical trial exploring this further would not be feasible.

It is likely that many of the girls in our study who were classified as having ENP actually had either slowly progressive CPP or presented to an endocrinologist too late to obtain any height benefit from treatment, and so represent an untreated control to some extent. It is reassuring that the untreated girls with ENP did not have higher rates of psychological distress than the treated girls with $\mathrm{CPP}$ at least in the short term, even though more of them had achieved menarche both at diagnosis and during the follow-up period.

In our study, girls across all groups reported a decrease in perceived physical competence and an increase in perceived maternal acceptance on the Harter scale 1 year af-

Short-Term Psychological Outcomes of Precocious Puberty ter diagnosis compared to baseline. The etiology of the decline in perceived physical competence is unclear. Perception of self-competence is influenced by environmental and developmental factors such as parenting behaviors, feedback from teachers, and the cognitive, social, and behavioral development of the child [37]. That this decline was observed in all 3 groups, including girls with $\mathrm{CPP}$ who were being treated, suggests that this phenomenon may not be related to pubertal status per se. Likewise, the reason for the increase in perceived maternal acceptance across all groups is unclear. The literature is conflicting as to whether scores on measures of self-concept change over time in children in the general population. It is well documented that younger children tend to be overly optimistic of their competence, and it appears that as cognitive skills improve with age, children are able to evaluate themselves with better accuracy [38]. Harter's original data for the Pictorial Scale of Perceived Competence and Social Acceptance for Young Children demonstrates stability in scores from preschool to second grade [19]. This finding was confirmed in one study, which noted stable self-perceptions in children from age 5 to 8 years using the Harter scale [39]. However, another study reported a decline in peer acceptance from preschool to second grade along with an increase in physical competence from preschool to kindergarten [38]. Given these conflicting reports, it is impossible to say whether the changes observed in our girls would have occurred regardless, or whether they were in some way related to the fact that they were being followed for early puberty. An additional caveat regarding our findings is that the girls who completed follow-up were 8.8 years old on average, which is slightly older than the age range for which the Harter scale is designed (i.e., preschool to second grade).

Lack of differences in maternal psychological functioning at follow-up may reflect selective attrition and overall small sample size, as fewer mothers of girls with PA completed follow-up assessments and the ones who returned did not differ from mothers of girls with CPP and ENP on baseline testing. Mothers who completed follow-up also had lower levels of baseline reported anxiety than mothers who only completed initial assessments. It is not surprising that the majority of subjects for whom we were unable to obtain 1-year follow assessments were in the PA and ENP groups as these children were not offered treatment and reassurance was provided to their parents at the time of diagnosis. It is interesting that all mothers reported an increase in negative affect at the time of follow-up. The relationship between this change over time and their daughters' pubertal status is unclear. 
Whether this is unique to mothers of daughters or also occurs in fathers and in mothers with sons of the same age and/or pubertal status as our subjects is unknown. Regardless, this was an unexpected finding and merits additional investigation.

There are a number of limitations to our study. First, the power was low to detect small changes between groups, so it is possible that the psychological profiles of the girls differed at follow-up but were not statistically detected. Additionally, the size of our sample precluded our ability to determine whether individual scores were correlated to specific Tanner stages in our CPP cohort. Second, a significant number of girls and mothers were lost to followup, despite multiple attempts to obtain the 1-year assessments. This could potentially represent a reduced degree of anxiety or stress and a feeling that follow-up was unnecessary and thus skew the results. Nevertheless, there were no significant differences between those who participated in follow-up and those who did not. Third, we lacked a prepubertal comparison group, which would have been useful to determine if the decline in perceived physical competence was related to puberty rather than age. Finally, the necessity of using the same instruments at both times to examine change means that our subjects were slightly older on average than the age group for whom the Harter scale was initially designed and validated.

\section{Conclusion}

To our knowledge, our study is the first to compare the psychological characteristics of girls with treated CPP, PA, and ENP over time. We found no convincing evi- dence of psychological distress in girls with variations of early puberty either at baseline or after 1 year, although the universal decline in perceived physical competence warrants further investigation. Our results indicate that girls with CPP, PA, and ENP have similar psychological functioning despite treatment of girls with CPP and progression of pubertal development in girls with PA and ENP. Whether 1-year follow up is representative of later outcome in these children is unknown. Regardless, our results do not support concerns regarding deleterious psychological consequences of early puberty in girls, at least in the short term, and provide encouraging information for families and providers. Additional large-scale, long-term prospective studies are needed in order to further elucidate the psychological impact of precocious puberty on girls and their mothers.

\section{Acknowledgments} grant.

Dr. Schoelwer was supported by NIH 2 T32DK065549 training

\section{Disclosure Statement}

The authors have no conflicts of interest relevant to this article to disclose.

\section{Funding Sources}

Funded by investigator (E.A.E.)-initiated grant \#1105005322 from Endo Pharmaceuticals.

\section{References}

1 Berenbaum SA, Beltz AM, Corley R: The importance of puberty for adolescent development: conceptualization and measurement. Adv Child Dev Behav 2015;48:53-92.

2 Graber JA, Seeley JR, Brooks-Gunn J, Lewinsohn PM: Is pubertal timing associated with psychopathology in young adulthood. J Am Acad Child and Adolesc Psychiatry 2004; 43:718-726.

-3 Stice E, Presnell K, Bearman SK: Relation of early menarche to depression, eating disorders, substance abuse, and comorbid psychopathology among adolescent girls. Dev Psychol 2001;37:608-619.

4 Galvao TF, Silva MT, Zimmermann IR, Souza KM, Martins SS, Pereira MG: Pubertal timing in girls and depression: a systematic review. J Affect Disord 2014;155:13-19.
- 5 Trepanier L, Juster RP, Marin MF, Plusquellec P, Francois N, Sindi S, Wan N, Findlay H, Schramek T, Andrews J, Corbo V, Dedovic K, Lupien S: Early menarche predicts increased depressive symptoms and cortisol levels in Quebec girls ages 11 to 13. Dev Psychopathol 2013;25:1017-1027.

-6 Toffol E, Koponen P, Luoto R, Partonen T: Pubertal timing, menstrual irregularity, and mental health: results of a population-based study. Arch Womens Ment Health 2014;17: 127-135.

7 Blumenthal H, Leen-Feldner EW, Babson KA, Gahr JL, Trainor CD, Frala JL: Elevated social anxiety among early maturing girls. Dev Psychol 2011;47:1133-1140.
8 Copeland W, Shanahan L, Miller S, Costello EJ, Angold A, Maughan B: Outcomes of early pubertal timing in young women: a prospective population-based study. Am J Psychiatry 2010;167:1218-1225.

-9 Mrug S, Elliott MN, Davies S, Tortolero SR, Cuccaro P, Schuster MA: Early puberty, negative peer influence, and problem behaviors in adolescent girls. Pediatrics 2014;133:7-14.

10 Chen M, Eugster EA: Central precocious puberty: update on diagnosis and treatment. Paediatr Drugs 2015;17:273-281.

11 Carel JC, Eugster EA, Rogol A, Ghizzoni L, Palmert MR: Consensus statement on the use of gonadotropin-releasing hormone analogs in children. Pediatrics 2009;123:e752-e762. 
12 Dorn LD, Rose SR, Rotenstein D, Susman EJ, Huang B, Loucks TL, Berga SL: Differences in endocrine parameters and psychopathology in girls with premature adrenarche versus ontime adrenarche. J Pediatr Endocrinol Metab 2008;21:439-448.

13 Dorn LD, Hitt SF, Rotenstein D: Biopsychological and cognitive differences in children with premature vs. on-time adrenarche. Arch Pediatr Adolesc Med 1999;153:137-146.

14 Sontag-Padilla LM, Dorn LD, Tissot A, Susman EJ, Beers SR, Rose SR: Executive functioning, cortisol reactivity, and symptoms of psychopathology in girls with premature adrenarche. Dev Psychopathol 2012;24:211223.

15 Xhrouet-Heinrichs D, Lagrou K, Heinrichs C, Craen M, Dooms L, Malvaux P, Kanen K, Bourguignon JP: Longitudinal study of behavioral and affective patterns in girls with central precocious puberty during long-acting triptorelin therapy. Acta Paediatrica 1997; 86:808-815.

16 Mazur T, Clopper RR: Pubertal disorders. Psychology and clinical management. Endocrinol Metab Clin North Am 1991;20:211230.

-17 Schoelwer MJ, Donahue KL, Bryk K, Didrick P, Berenbaum SA, Eugster EA: Psychological assessment of mothers and their daughters at the time of diagnosis of precocious puberty. Int J Pediatr Endocrinol 2015;2015:5.

$>18$ Kovacs M: Rating scales to assess depression in school-aged children. Acta Paedopsychiatrica $1981 ; 46: 305-315$.

19 Harter S, Pike R: The pictorial scale of perceived competence and social acceptance for young children. Child Dev 1984;55:19691982.

20 Achenbach TM, Rescorla LA: Manual for the ASEBA School-Age Forms and Profiles. Burlington, University of Vermont Research Center for Children, Youth, and Families, 2001.
1 McCrae RR CP: Brief versions of the NEOPI-3. J Individ Differ 2007;28:116-128.

22 Lovibond PF, Lovibond SH: The structure of negative emotional states: comparison of the Depression Anxiety Stress Scales (DASS) with the Beck Depression and Anxiety Inventories. Behav Res Ther 1995;33:335-343.

23 Watson D, Clark LA, Tellegen A: Development and validation of brief measures of positive and negative affect: the PANAS scales. J Pers Soc Psychol 1988;54:1063-1070.

24 Walvoord EC: The timing of puberty: is it changing? Does it matter? J Adolesc Health 2010;47:433-439.

25 Dorn LD: Psychological and social problems in children with premature adrenarche and precocious puberty; in Pescovitz $\mathrm{OH}$, Walvoord EC (eds): When Puberty is Precocious. Totawa, Humana Press, 2007, 309-327.

26 Nacinovich R, Buzi F, Oggiano S, Rossi S, Apada S, Broggi F, Pilotta A, Neri F, Bomba M. Body experiences and psychopathology in idiopathic central precocious and early puberty. Minerva Pediatr 2016;68:11-18.

27 Sonis WA, Comite F, Blue J, Pescovitz OH, Rahn CW, Hench KD, Cutler GB Jr, Loriaux DL, Klein RP: Behavior problems and social competence in girls with true precocious puberty. J Pediatr 1985;106:156-160.

28 Jaackson PL, Ott MJ: Percieved self-esteem among girls diagnosed with precocious puberty. J Pediatr Nurs 1990;5:190-203.

29 Ehrhardt AA, Meyer-Balhlburg HF, Bell JJ, Cohen SF, Healey JM, Stiel R, Feldman JF, Morishima A, New MI: Idiopathic precocious puberty in girls: psychiatric follow-up in adolescence. J Am Acad Child Adolesc Psychiatry 1984;23:23-33.

30 Sonis WA, Comite F, Pescovitz OH, Hench K, Rahn CW, Cutler GB Jr, Loriaux DL, Klein RP: Biobehavioral aspects of precocious puberty. J Am Acad Child Psychiatry 1986;25: 674-679.
1 Galatzer A, Beth-Halachmi MA, Kauli R, Laron Z: Intellectual function of girls with precocious puberty. Pediatrics 1984;74:246-249.

32 Eugster EA: The use of gonadotropin-releasing hormone analogs beyond precocious puberty. J Pediatr 2015;167:481-485.

33 Guaraldi F, Beccuti G, Gori D, Ghizzoni L: Long-term outcomes of the treatment of central precocious puberty. Eur J Endocrinol 2016;174:R79-R87.

34 Lazar L, Meyerovitch J, de Vries L, Phippil M, Lebenthal Y: Treated and untreated women with idiopathic precocious puberty: longterm follow-up and reproductive outcome between the third and fifth decades. Clin Endocrinol 2014;80:570-576.

35 Thornton P, Silverman LA, Geffner ME, Neely K, Gould E, Danoff TM: Review of outcomes after cessation of gonadotropin-releasing hormone agonist treatment of girls with precocious puberty. Pediatr Endocrinol Rev 2014:11:306-317.

36 Mul D, Versluis-den Bieman HJ, Slijper FM, Oostdijk W, Waelkens JJ, Drop SL: Psychological assessments before and after treatment of early puberty in adopted children. Acta Paediatrica 2001;90:965-971.

>37 Jambunathan S, Hurlbut NL: Gender comparisons in the perception of self-competence among four-year-old children. J Genet Psychol 2000;161:469-477.

38 Mantzicopoulos P: Younger children's changing self-concepts: boys and girls from preschool through second grade. J Genet Psychol 2006;167:289-308.

39 Verschueren K, Marcoen A, Buyck P: Fiveyear-olds' behaviorally presented self-esteem: relations to self-perceptions and stability across a three-year period. J Genet Psychol 1998;159:273-279.
Short-Term Psychological Outcomes of Precocious Puberty
Horm Res Paediatr 